\title{
Geopolítica e Desenvolvimento em Petty, Hamilton e List
}

\author{
Geopolitics and Development in Petty, Hamilton and List
}

\author{
RAPHAEL PADULA* \\ JOSÉ LUÍS FIORI**
}

RESUMO: Este artigo argumenta que as visões de Petty, Hamilton e List consideravam o problema da "ameaça externa" dos países uma dimensão fundamental do seu desenvolvimento econômico e, por isso, pensavam as economias nacionais não apenas em termos de progresso econômico, mas também como um instrumento para a independência política, a soberania militar e a segurança nacional. Assim, a "ameaça externa" é utilizada para priorizar objetivos estratégicos e direcionar a estrutura produtiva e a geração de renda para determinados setores considerados mais relevantes. Por fim, argumenta-se que essa concepção se encontra ausente no pensamento latino-americano e origina a disciplina de Economia Política Internacional.

PALAVRAS-CHAVE: Economia Política Internacional; Desenvolvimento; Segurança; Nacionalismo Econômico.

ABSTRACT: This paper argues that the views of Petty, Hamilton, and List considered the "external threat" matter of countries a fundamental dimension of their economic development, and therefore thought national economies not only in terms of economic progress, but also as an instrument for political independence, military sovereignty and national security. Thus, the "external threat" is used to prioritize strategic objectives and direct the productive structure and the generation of income to certain sectors considered more relevant. Finally, it is argued that this conception is absent in Latin American thought and originates the discipline of International Political Economy.

KEYWORDS: International Political Economy; Development; Security; Economic Nationalism.

JEL Classification: F59; F52; B12.

\footnotetext{
* Professor Adjunto e Coordenador da Pós-Graduação em Economia Política Internacional (PEPI) do Instituto de Economia da Universidade Federal do Rio de Janeiro - IE/UFRJ, Rio de Janeiro/RJ, Brasil. E-mail: padula.raphael@gmail.com.

** Professor Titular de Economia Política Internacional (PEPI), do Instituto de Economia da Universidade Federal do Rio de Janeiro / IE/UFRJ, Rio de Janeiro/RJ, Brasil. E-mail: jlfiori@uol.com.br. Submetido: 11/Janeiro/2018; Aprovado: 26/Julho/2018.
} 
"Em última instância os processos de desenvolvimento econômico são lutas de dominação"

(Max Weber, Escritos Políticos, Folios Ediciones, México, 1982, vol I, p.18).

\section{INTRODUÇÃO: A PERSPECTIVA DO "PODER"}

Nas últimas duas décadas da história latino-americana, o problema do desenvolvimento voltou a ocupar o topo da sua agenda das lutas políticas. Com uma radicalização sem precedentes entre as forças partidárias do liberalismo econômico e da desmontagem dos Estados em nome dos mercados e dos indivíduos, e as forças partidárias do fortalecimento dos Estados como núcleo estratégico de projetos nacionais de longo prazo que incluam as populações mais pobres do continente. No Brasil, é comum que este confronto assuma a forma de um debate entre economistas ortodoxos e heterodoxos, a respeito de políticas macroeconômicas. Mas este artigo não se propõe participar diretamente deste debate, nem questionar a importância dos seus argumentos e propostas. Se propõe apenas a chamar a atenção para um outro ângulo do problema geral do desenvolvimento econômico e político das nações: a importância da sua inserção geopolítica para o desenho e sucesso de suas estratégias de desenvolvimento ${ }^{1}$. Em particular no caso dos Estados nacionais que disponham de grandes territórios e populações com intensa dotação de recursos energéticos e alimentares, e que enfrentem grandes desafios internos junto com grandes "ameaças externas" 2 .

Karl Marx considerava que William Petty teria sido o verdadeiro "pai” da "economia política clássica", por ter sido quem formulou pela primeira vez o conceito de "excedente econômico", como sendo o verdadeiro móvel e objetivo da atividade produtiva das nações (ASPROMOURGOS, 1996). Mas Petty também foi

\footnotetext{
${ }^{1}$ Perspectiva que vem sendo estudada há alguns anos pelo Grupo de Economia Política Internacional do Instituto de Economia, e hoje do Programa de Pós-Graduação em Economia Política Internacional - PEPI da UFRJ. Uma pesquisa de longo fôlego que já tem algumas décadas e resultou na publicação de inúmeros artigos em revistas especializadas, e de pelo menos três livros que tratam diretamente do assunto: Fiori, J.L. (Org.) "Estados e Moedas no Desenvolvimento das Nações", Editora Vozes, Petrópolis 1999; Fiori, J.L e Madeiros, C. (Org.) "Polarização Mundial e Crescimento", Editora Vozes, Petrópolis, 2001; e Fiori, J.L, “História, Estratégia e Desenvolvimento”, Editora Boitempo, São Paulo, 2014. Vide também a página do Grupo de Pesquisa registrado no CNPq "Poder Global e Geopolítica do Capitalismo", www.poderglobal.net.

2 "Se existisse um denominador comum entre todos os países de forte desenvolvimento econômico, com certeza seria a existência de um grande desafio ou inimigo externo competitivo, responsável pela existência de uma orientação estratégica defensiva e permanente, envolvendo' quase sempre, uma dimensão político-militar e uma competição acirrada pelo controle das 'tecnologias de ponta" (Fiori, J.L, "Estado e desenvolvimento na América Latina: notas para um novo programa de pesquisa”. CEPAL/ IPEA, novembro de 2013, p.21).
} 
o autor que relacionou, de forma mais direta e explícita, a questão dos tributos e do cumprimento das responsabilidades do Estado com a defesa do seu território e com a segurança dos seus cidadãos, antes de qualquer outra coisa. Nesse sentido, o Estado, suas políticas e a questão do poder seriam reconhecidos e relacionados por Petty com a necessidade de multiplicação da riqueza das nações.

Da mesma forma que Petty, Alexander Hamilton e Friedrich List também pensaram o problema do desenvolvimento econômico dos seus países a partir de uma perspectiva que privilegiava a questão do "poder" nacional e internacional dos mesmos, dentro de um sistema de competição interestatal, onde se impunha acumular poder para acumular riqueza e vice-versa. $\mathrm{Na}$ visão desses autores, os Estados deveriam estar sempre pensando na sua defesa e na sua capacidade de superar os desafios externos através de acumulação sem fim de poder e riqueza. Assim, para eles, a economia nacional, suas mudanças estruturais e a expansão do comércio exterior, devia ser pensada como um caminho para alcançar o objetivo estratégico da independência política internacional dos seus países, diminuindo a sua dependência/vulnerabilidade externa econômica e militar, e superando seu atraso ante a Estados concorrentes (rivais) mais poderosos e avançados militar e economicamente. Nesta forma de olhar, poder e riqueza são relacionais e assimétricos entre Estados, e ao mesmo tempo pensados de forma indissociável e sinérgica. Questões de geopolítica, segurança e desenvolvimento se apresentam como interconectadas. E é a partir da identificação da existência de ameaças externas que os autores vão justificar a necessidade de políticas que direcionem as atividades produtivas e a geração de renda para determinados setores econômicos e grupos que consideram estratégicos e mais relevantes, com o objetivo de manter e aumentar cada vez mais a coesão social interna de suas sociedades, sobretudo com relação aos seus desafios externos.

Deste ponto de vista, Petty, Hamilton e List podem ser considerados como pais ou precursores da Economia Política Internacional, como uma disciplina voltada para as relações entre economia e política internacional, como propôs Susan Strange (1970), ou, de forma mais ampla, entre poder e riqueza no sistema internacional. Uma dimensão que esteve sempre ausente ou muito distante das discussões brasileiras e latino-americanas sobre desenvolvimento e desenvolvimentismo, fosse no caso da teoria estruturalista de Raúl Prebisch e seus discípulos, fosse no caso da Teoria da Dependência de André G. Frank e Fernando H. Cardoso e seus discípulos.

Este artigo se divide em quatro seções, além desta introdução, com uma seção dedicada a cada um dos autores citados e uma apresentando as conclusões e considerações finais, argumentando pela retomada do pensamento latino-americano incorporando a percepção de ameaça geopolítica como um elemento fundamental das suas novas reflexões e estratégias de desenvolvimento no século XXI.

\section{WILLIAM PETTY: INGLATERRA VERSUS FRANÇA E HOLANDA}

Nascido na Inglaterra, Petty (1620-1687) é conhecido por ter sido um médico, filósofo, cientista e economista, que serviu na Irlanda ocupada pela Commonwealth 
de Oliver Cromwell. Além de questões político-religiosas terem sido importantes na Inglaterra e na Europa, o período em que viveu foi profundamente marcado por constantes guerras e competição interestatais. Um quadro que contribuiu para a formação dos Estados-Nacionais modernos, a centralização do poder e a presença de guerras predominantemente por motivos políticos, e a ascensão de potências como as Províncias Unidas e a França ${ }^{3}$.

Entre Holanda e Inglaterra, a disputa pelo poder, espaços marítimos e mercados, foi se desenvolvendo, envolvendo quatro guerras Anglo-Holandesas, três delas durante a vida de Petty ${ }^{4}$. Os Atos de Navegação de Cromwell (1651) impulsionaram o desenvolvimento da indústria naval (e ramos produtivos conexos) e o poder militar-naval britânicos, essenciais para a guerra e para as atividades comerciais marítimas. Consequentemente, acirraram a competição anglo-holandesa. Assim, viveu no período histórico no qual os Estados tinham como preocupação central a guerra e a segurança em um ambiente competitivo de ameaça mútua, e a economia seria um instrumento essencial para a capacidade de gerar recursos e tecnologias, tributação interna e externa, e de gerar divisas através do comércio exterior baseado na exportação manufatureira. Foi nesse período que se lançaram as bases do poder bélico e industrial-tecnológico britânicos, objetos da reflexão de Petty. Além disso, carregou reconhecida influência do empirismo científico de Francis Bacon, apegando-se a fatos e números, e de Thomas Hobbes, de quem foi secretário e se tornou amigo, marcando profundamente sua concepção sobre o papel do Estado em busca de prosperidade e segurança.

Suas principais obras são: Tratado Sobre Impostos e Contribuições de 1662; Verbum Sapienti de 1664 (pequeno tratado publicado em 1691); e Aritmética Política, de aproximadamente 1676 (publicado postumamente em 1690). A última é reconhecida pelas suas contribuições à Economia, ao passar por reflexões metodológicas, estatística e de sistematização do cálculo da renda e da riqueza nacionais. A obra de Petty apresenta contribuições importantes sobre como a divisão social do trabalho, o avanço da produtividade e o investimento em infraestrutura podem gerar redução de custos na produção de bens básicos, tendo impactos por toda a economia e favorecendo o direcionamento para atividades que ele aponta como mais rentáveis - manufatura e comércio.

No entanto, a reflexão fundamental à qual a obra de Petty se dedica é sobre como a Inglaterra poderia superar seus principais rivais, Holanda e França, através da ação política do Estado, buscando aumentar seu poder e riqueza em um ambiente que tem a guerra e a competição interestatais como elementos centrais. No prefácio original escrito por Petty, o autor explicita sua preocupação com a percepção difundida - que busca refutar através de "números, peso e medida" - de que a Inglaterra tem diversos problemas econômicos e ainda "os holandeses estão em nossos calcanhares na corrida pelo poderio naval; os franceses estão perto demais

\footnotetext{
${ }^{3}$ Este ambiente pode ser ilustrado por diversas guerras, inclusive as encerradas pela Paz de Vestfália.

${ }^{4}$ Nos anos de 1652-1654, 1665-1667, 1672-1674 e 1781-1784.
} 
tanto dos holandeses quanto dos ingleses e parecem tão ricos e poderosos que só por clemência não devoram seus vizinhos [...]" (1690, p.141). Assim, as ameaças geopolíticas externas, a segurança e sobrevivência da Inglaterra, balizam a reflexão do autor sobre o progresso econômico, a geração de excedente e mudanças estruturais na economia. Sua aritmética política buscava mostrar e servir de instrumento à acumulação de poder e riqueza, ou mostrar como o progresso da economia nacional poderia ser um instrumento para isso, tornando a Inglaterra mais poderosa em termos militares, principalmente defensivos (incluindo a capacidade de financiar uma guerra). Ou seja, uma aritmética política do poder e da riqueza, da segurança e do desenvolvimento, para o poder britânico buscar superar seus rivais. Conforme apontado em Fiori (2015, p.53):

No momento em que Petty publicou sua obra, a Inglaterra era uma potência de segunda ordem, e se sentia ameaçada pela França e pela Holanda. [...] tinha uma grande preocupação que se transformou no ponto de partida de toda a sua teoria: a necessidade de defender o território inglês, aumentando sua produtividade e o seu produto nacional. Por isto, sua economia política introduz, pela primeira vez, o conceito de "excedente econômico" como principal instrumento do poder do Estado, e rompe definitivamente com a tradição do pensamento mercantilista.

$\mathrm{Na}$ sua primeira obra, ao discorrer sobre as diversas espécies e os principais encargos públicos, o primeiro apontado é o encargo militar: a defesa por terra e por mar, a paz interna e externa, e a "vindicação honrosa das ofensas de outros Estados" (Petty, 1662, p.33). Aponta que "o mais comum é que [o encargo militar] seja ordinariamente tão grande quanto qualquer outro ramo do todo, mas extraordinariamente (isto é, em tempo de guerra ou temor de guerra) é, de longe, o maior". Ainda, afirma que "estar inteiramente sempre em postura de guerra é a maneira menos custosa de evitar que a guerra venha de fora”, mostrando a importância da força dissuasória como elemento defensivo (Idem).

Desde sua primeira obra, Petty $(1662$, p.38) destaca a importância da capacidade estatal de extrair tributos da população para financiar guerras, especialmente em momentos críticos. Na introdução de Verbum Sapient (1664), fala sobre a importância da tributação para financiar a guerra com a Holanda, caso esta continuasse (fato ocorrido). Nesse sentido, a preocupação com os gastos em segurança são objeto do capítulo VIII, enquanto o capítulo IX versa sobre a aceitação de impostos extraordinários. Para isso, aponta a importância do incremento das atividades manufatureiras que tragam divisas através do comércio exterior, da comparação da riqueza entre Inglaterra e Holanda - em termos de produção, produtividade, valor das terras, habitações, navios, mercadorias e dinheiro -, e como seu país poderia superar possíveis desvantagens de computo geral relativo (IDEM, p.131). É para o objetivo central de financiar a guerra com a Holanda que o capítulo X se dedica a "Como empregar as pessoas e a finalidade desse emprego", ou seja, sobre a economia nacional como elemento estratégico para a guerra. Aponta 
ainda a importância da "produção de alimentos e gêneros de primeira necessidade para toda a população do país, por poucos braços”, quer pela introdução de novas técnicas ou pela intensificação do trabalho, barateando o preço destes artigos e, através da autossuficiência, liberando mão de obra para trabalhar em outras atividades, incluindo governo (burocracia), judiciário, educação e defesa, mas também nas atividades mais rentáveis que seriam a indústria e comércio: na produção manufatureira que possa trazer dinheiro do exterior - "suprindo nossas necessidades e de qualquer outro lugar" - até que seu país tivesse mais dinheiro (e poder econômico) que seus vizinhos (Idem, p.133).

Em Aritmética Política, o capítulo I se intitula: "Que um país pequeno, com pouca gente, pode, por sua Situação [Geográfica], por seu Comércio e pelas Políticas que adota, ser equivalente em Riquezas e Poderio a outro com território muito mais amplo e população maior, e particularmente como a navegação e o transporte marítimo, de maneira excelente e fundamental, conduzem a isso". Riqueza e poder relativos estão no centro da sua análise, dedicada principalmente à comparação entre Holanda, França e Inglaterra. Acredita que a diferença entre poder e riqueza, e em território e população, "deriva principalmente da situação geográfica, da atividade econômica e das políticas adotadas” (Petty, 1690, p.148), especialmente em relação aos equipamentos e instalações navais (Idem, p. 151). A competição bélica e mercantil naval, na disputa pelos mares, ganha relevância em sua análise. Daí Petty começa a fazer uma relação e comparação quantitativa entre países, usando diversas variáveis, sozinhas e combinadas: frotas (em termos de toneladas, capacidade e valor em libras), valor das exportações, receitas reais provenientes tanto das exportações quanto dos tributos sobre a população, taxas de juros, populações, terras férteis e territórios. Destaca ainda a necessidade de pensar principalmente em termos de evolução recente da riqueza e do poderio dos países, mencionando que enquanto a França mal dobrou sua riqueza, a Holanda decuplicou (Idem, p.148-50).

Petty assinala que a situação geográfica relativa dos territórios demanda diferentes necessidades e gastos em forças de defesa. Destaca a geografia vantajosa na Holanda, em termos de relevo (baixo e plano) e fertilidade das terras, o que favorece a produtividade agrícola, que as pessoas vivam próximas e com mobilidade de transporte comercial, economizando tempo e facilitando a defesa mútua (Petty, 1690, p.151). Os investimentos em infraestrutura teriam papel importante tanto no sentido de diminuir custos de produção e gerar riqueza (1662, p.35), quanto na integração e defesa do território (1690, p.151). A posição geográfica da Holanda também se mostra favorável ao comércio, para ter uma maior participação e administração nos transportes de mercadorias no mundo. A facilidade de acesso a rios e mares, de qualquer parte do território, facilita e barateia as despesas de transporte e comunicação. A posição insular favorece também a defesa do país, e a capacidade de manter navios em portos comprometendo menos homens.

Para Petty, a produção manufatureira gera mais ganhos que a agrícola, e o comércio dos produtos fabricados em território nacional para o mundo geram mais ganhos ainda. O autor afirma que é conhecido que todo país prospera com a ma- 
nufatura produzida a partir de matérias-primas no seu território. A Holanda, por sua vez, através de seu extenso comércio e poder naval, "leva todas as matérias-primas para serem processadas em seu país e as levam de volta, manufaturadas, até para o mesmo de onde vieram" (Idem, p153).

Num contexto interestatal competitivo e conflituoso, o autor aponta que o comércio superavitário teria papel fundamental para gerar divisas (metálicas) que podem ser gastas a qualquer tempo. Assim, além da tributação da população, o comércio internacional superavitário, baseado na produção e exportação de manufaturas, seria fundamental para acumular poder relativo em termos de recursos para financiar o poder militar e as guerras. O progresso econômico, a geração de excedente e a mudança estrutural, representados pelo maior direcionamento e participação de atividades manufatureiras na produção e nas exportações, teriam papel fundamental nisso ${ }^{5}$.

Enquanto o capítulo IV de sua principal obra dedica-se a mostrar que a Inglaterra possui poder e riqueza relativamente iguais aos da França, os capítulos $\mathrm{V}$ a X discorrem sobre como os impedimentos à grandeza da Inglaterra são apenas contingentes e removíveis, focando em políticas que podem levar à superação da Holanda. Os impedimentos estariam em seus territórios distantes com divisões de poderes entre eles (um legislativo para Inglaterra, outro para Escócia e outro para Irlanda), sendo um óbice à união de identidade e de interesses. Isto gera maiores dificuldades de segurança e defesa (que recaem sobre a Inglaterra), além da perda das vantagens em termos de poder e riqueza que seriam geradas por uma união política e econômica. Petty se preocupava com o comércio internacional como fonte de acumulação de poder e riqueza nacionais, atrelado ao avanço produtivo interno e geração de excedente econômico, ao mesmo tempo em que se preocupava com a boa administração das contas do Estado. A tributação sobre importação deveria se dar de forma a deixar mais caros todos os produtos que podem ser produzidos internamente, assim como sobre bens supérfluos. As manufaturas deveriam ser tratadas com benevolência, e as invenções justificariam o monopólio como recompensa (Petty, 1662, p.68; 89). Ele chegava a afirmar que a proibição de importações seria necessária caso existisse um déficit comercial muito grande. Enfim, preocupava-se com os fundamentos da economia nacional (e da geração de excedente) como base para o poder político-militar de sua Inglaterra.

É importante notar que diante de possíveis conflitos de interesses e distributivos internos, Petty utiliza a presença de uma ameaça geopolítica para justificar políticas que incentivem as atividades que considera mais rentáveis para o progresso econômico e para o interesse nacional, mas mantendo a coesão interna. Petty

\footnotetext{
${ }^{5}$ Petty (1690, p.155) conclui que a situação geográfica deu à Holanda a navegação; a navegação lhes deu o comércio; o comércio lhes deu a riqueza através de toda a manufatura que podem produzir; e com isso o excedente, fazendo o resto do mundo trabalhar produzindo matérias-primas para suas manufaturas. Mas destaca, neste processo, a importância do papel das políticas estatais baseadas em vantagens naturais ou não.
} 
também observou a importância de políticas concernentes à distribuição desigual da riqueza, pois acreditava que esta seria uma das causas da guerra civil e de conturbações internas dos Estados, que podem enfraquecê-los (1662, p.39).

\section{ALEXANDER HAMILTON: ESTADOS UNIDOS}

\section{ANTE A INGLATERRA E A ESPANHA}

Um dos founding fathers e Primeiro Secretário de Tesouro (1789-1795) dos EUA, Hamilton (1757-1804) foi o principal autor e organizador do Federalist (1787) e escreveu uma série de relatórios apresentados ao Congresso. Participou de forma importante (militar e politicamente) da Guerra de Independência (1775-1783) travada pelas Treze Colônias contra a Inglaterra, que foi impulsionada pela Guerra dos Sete Anos (entre França e Inglaterra pelas colônias norte-americanas), e consequente arrocho que a Inglaterra impôs às colônias com o objetivo de reparar seus gastos - tendo a Revolução Industrial como pano de fundo. Assim, viveu num período de intensa rivalidade e luta pela independência dos EUA ante a Inglaterra, que, de forma implícita ou explícita, manteve-se até pelo menos a Guerra Civil (1861-1865), enquanto a última seguiu influenciando grupos internos. É interessante notar que a obra A Riqueza das Nações de Adam Smith foi publicada em 1776, um ano após a independência estadunidense, sendo usada para difundir a tese do livre comércio como meio para a riqueza das nações e a paz internacional entre a opinião política e pública em diversos países ${ }^{6}$. Nos EUA passou a ser protagonizado o debate entre, de um lado, o grupo agroexportador do Sul, partidário do "Sistema Britânico" livre-cambista e de laços econômicos e políticos estreitos com a Inglaterra, e, de outro, industrialistas protecionistas do Norte, do "Sistema Americano" de Economia Política, favoráveis a maior autonomia e independência política.

Hamilton se destaca na defesa de uma política econômica promotora da indústria como motor do progresso econômico nacional, com especial atenção à proteção à indústria nascente. Seu Relatório sobre as manufaturas (1791) aponta uma série de medidas para o florescimento da indústria nacional, que espalhariam progresso para as demais atividades econômicas (agricultura e comércio), através da formação de um mercado interno dinâmico e da divisão social da produção, em um país relativamente atrasado. Por isso, do ponto de vista das reflexões sobre desenvolvimento econômico, Hamilton é usualmente referido como um "industrialista", "protecionista" e "nacionalista econômico". O mesmo vale para interpretações sobre sua visão sobre o papel do crédito público, presente em seu Relatório sobre o Crédito Público (1790), em que aponta a sua importância para o cresci-

\footnotetext{
${ }^{6}$ Pouco antes de Smith, na Inglaterra, James Stuart apontou a importância da indústria e da proteção à indústria nascente para o progresso da economia nacional, na sua obra An Inquiry into the Principles of Political Economy being an Essay on the Science of Domestic Policy in Free Nations, de 1676. Mas teve sua obra ofuscada pela publicação de Smith, embora tenha tido muita influência entre os economistas do Sistema Americano de Economia Política e sobre List.
} 
mento e interconexão das atividades econômicas (indústria, agricultura e comércio) e do sistema econômico nacional.

Hamilton (1791, p.92) afirma que a prosperidade coletiva das manufaturas e da agricultura estão intimamente interconectadas e que existe uma "íntima correlação de interesses existente entre todos os setores de uma sociedade unida sob um mesmo governo - a infinita variedade de canais que servem para difundir a prosperidade de cada um aos demais e entre os demais [...]". Além de uma visão sistêmica sobre a economia nacional, a argumentação de Hamilton também é importante do ponto de vista político interno, no sentido de amalgamar interesses de grupos internos em torno de um projeto comum, em uma sociedade dividida e em um Estado recém-formado, diante de influências e interesses externos. Isto fica claro se recorrermos também à obra O Federalista.

Para o argumento central deste artigo, é importante destacar a ameaça geopolítica da Inglaterra e da Espanha, e do imperialismo das potências europeias de forma mais ampla, num ambiente competitivo e conflituoso internacional, como elementos centrais na reflexão de Hamilton sobre desenvolvimento, atrelada ao tema da independência política, da autonomia e defesa nacionais. Em O Federalista (1787), os números 2 ao 5, escritos por John Jay, dedicam-se especificamente aos perigos e influências advindas de forças externas. Mas Hamilton também aponta preocupações importantes nesse sentido, como destacamos a partir dos números 11, 24 e 25. O primeiro, "A Utilidade da União em Matéria de Relações Comerciais e uma Marinha", e os dois últimos, "Poderes Necessários para a Defesa Comum...”.

Ao observar um mundo dividido geograficamente e em termos de interesses políticos, Hamilton $(1787, \mathrm{n} .11)$ aponta a importância da União para emergir um Estado com poder político para fora, diante de ameaças externas, que deveria se tornar o árbitro nas relações da Europa com o continente americano - "capaz de inclinar a balança dos competidores europeus nesta parte do mundo conforme nossos interesses possam ditar", antecipando a Doutrina Monroe anunciada pelo Presidente ao Congresso em 1823. Mas também para formar um Estado com poder político para dentro, para modernizar e integrar a economia e o mercado nacional, através do progresso manufatureiro e do sistema de comércio e infraestrutura, para que se torne autossuficiente em todas as suas necessidades internas, e também impulsione as exportações. Para ele, o comércio baseado em commodities, com preço e demanda determinados externamente, seria um "comércio passivo", em que seus lucros seriam transferidos para os inimigos e perseguidores do país. Ainda, a diversificação produtiva impulsionada pela industrialização teria papel importante na redução da vulnerabilidade externa, pois o estancamento de demanda para quem produz uma pequena variedade interfere na venda de todos os produtos, nos preços, na balança comercial, e, consequentemente, em toda economia nacional. Assim, seria importante a diversificação produtiva interna e das exportações, para uma inserção internacional favorável e redução da vulnerabilidade externa política e econômica (Idem).

Este argumento é reforçado em seu Relatório sobre as manufaturas, ao vislumbrar a implantação de um sistema manufatureiro florescente nos EUA; Hamilton (1791, p.55) aponta que um país puramente agrícola depende das condições do 
país que demanda seus excedentes, pois há a possibilidade deste: restringir o comércio, sofrer crises, sofrer quedas ou ascensões na produção manufatureira ou agrícola que flutuem sua demanda agrícola, e, ainda, pode haver guerras que impossibilitem o fluxo de mercadorias. Isto provoca desestímulos ao investimento e à produção do excedente agrícola. Assim, afirma que o mercado interno é preferível ao externo, por ser mais seguro. E "para se criar tal mercado interno, não há outro recurso senão promover os estabelecimentos manufatureiros" que serão os consumidores dos excedentes agrícolas (Idem). Os estabelecimentos manufatureiros e os agrícolas estimulam o aperfeiçoamento técnico um do outro. Para Hamilton (1787, 1791), esta é a melhor forma de afastar influências e interesses externos. Assim, como aponta Earle (1986, p.235), "Hamilton conectou seu sistema econômico com segurança nacional".

Ele tinha uma visão clara de que o poder e a riqueza caminham juntos, de forma indissociável, de que o progresso industrial, a diversificação produtiva interna e do comércio, a autossuficiência na produção de bens necessários e estratégicos (como indústrias básicas e de defesa, por exemplo), estariam conectados ao aumento do poder, à diminuição da vulnerabilidade externa, à independência política (autonomia) e à segurança e defesa do Estado, como a guerra anterior mostrou e as que viriam mostrariam:

Não só a riqueza; mas a independência e a segurança de um país, parecem estar materialmente ligados à prosperidade das manufaturas. Toda nação, com vista a esses grandes objetivos, deve se esforçar para possuir dentro de si todos os elementos essenciais do abastecimento nacional. Estes compreendem os meios de subsistência, habitação e defesa [...].

A falta de uma Marinha, para proteger o nosso comércio exterior, enquanto não se remedie, continuará tornando-o uma fonte insegura e particularmente precária para o abastecimento de artigos essenciais, e há de fortalecer consideravelmente os argumentos em prol das manufacturas. (Hamilton, 1791, p.88-89).

Conforme aponta Earle (1986, p.233), o objetivo declarado por Hamilton era de promover as manufaturas para tornar os EUA independentes de outras nações para terem acesso seguro a artigos militares e essenciais.

Ao dedicar-se ao tema da defesa comum da União, Hamilton $(1787$, n.24) aponta que esta formaria um poder maior, com maior capacidade de recursos e de formar uma marinha para defender as treze colônias, inclusive em tempos de paz, quando é preciso estar preparado e afastar ameaças externas. Observa como principais ameaças externas a Inglaterra e a Espanha - autênticos poderes marítimos, principalmente com o desenvolvimento de sua capacidade de mobilidade -, suas colônias em países próximos e vizinhos, sem deixar de vislumbrar a hipótese de alianças entre estas potências e/ou destas com os "povos selvagens" de seus territórios vizinhos a oeste, que tendiam a ver os EUA como inimigos naturais. E afirma: "Em proporção ao nosso aumento de força, é provável, também se pode dizer certo, que a Grã-Bretanha e a Espanha aumentariam seus estabelecimentos militares em nossa vizinhança” (Idem). Hamilton (1791, p.45) também observou a importância 
de uma marinha forte para os EUA protegerem o comércio e o território, em tempos de paz e de guerra, tanto para garantir acesso a bens essenciais enquanto não produzidos internamente, quanto para apoiar o processo de avanço industrial.

Hamilton (1791, p.110), assim como List (1841), observa a importância do sistema de infraestrutura não só do ponto de vista do desenvolvimento industrial e interconexão do mercado nacional, mas também da capacidade de mobilidade para defesa.

Para Hamilton (1791, p.85) há (cinco) circunstâncias nas quais se pode eleger um bem como merecedor de atenção particular do Estado quanto à sua produção ${ }^{7}$, e uma delas refere-se à produção ligada à defesa (armas de fogo e armamentos militares). Esta deveria ser estimulada e cuidada pelo Estado, como um setor estratégico, para atender à demanda interna e não depender do abastecimento externo. O estímulo deveria se dar inclusive através de compras estatais que privilegiassem a indústria bélica nacional, e mesmo com o Estado se envolvendo na produção, pois, devido à sua importância e natureza, esta indústria não poderia ficar nas mãos dos interesses privados:

[...] deve, em seguida, merecer consideração legislativa se as fábricas de todas as armas de guerra necessárias não deveriam ser estabelecidas pelo governo, por conta própria. [...] Parece haver uma improvidência ao deixar esses instrumentos essenciais de defesa nacional para as especulações casuais de recursos de aventuras individuais, que podem ser menos invocados, neste caso, do que na maioria dos outros; sendo que os artigos em questão não são objetos de consumo ou uso privado ordinário e indispensável (Hamilton, 1791, p.86).

Os empréstimos em momentos de perigo público, especialmente de guerra externa, são vistos como recursos indispensáveis, mesmo para a mais rica das nações. $\mathrm{E}$ isso, em um país como esse que possui uma pequena riqueza ativa ou, em outras palavras, um capital monetário pequeno, a necessidade desse recurso deve, em tais emergências, ser proporcionalmente urgente. E como, por um lado, a necessidade de empréstimos em emergências particulares não pode ser duvidosa, por isso, por outro lado, é igualmente evidente que, para poder tomar emprestado em bons termos, é essencial que o crédito de uma nação deva estar bem estabelecido (HAMILTON, 1790, p.1).

\section{FRIEDRICH LIST: A ALEMANHA ANTE A INGLATERRA}

\footnotetext{
${ }^{7}$ (1) a capacidade do país de fornecer matéria-prima; (2) o grau no qual a natureza de uma manufatura admite substituição de trabalho manual por máquinas; (3) a facilidade de execução; (4) a extensão de usos para o qual o artigo pode ser aplicado; (5) sua subserviência a outros interesses, "particularmente o maior da defesa nacional". Quanto às matérias-primas, ele destaca em primeiro lugar o ferro, pela sua importância na composição das manufaturas, devendo ser restringida (tarifada) a sua exportação na forma bruta e estimulada a produção de produtos que o tenham como matéria-prima (Idem, p.20)
} 
Militante e economista político alemão, List (1789-1846) teve como principal obra o livro Sistema Nacional de Economia Política (1841). Viveu entre a Primeira e a Segunda Revolução Industrial, um período em que manufaturas e máquinas ascendiam crescentemente em importância para o desenvolvimento nacional e para a vida cotidiana, mas também para o poder militar.

Sua Alemanha se encontrava fragmentada politicamente em diversos estados. Foi uma época de nacionalismo na qual a Europa presenciava frequentes conflitos e ascensão de grandes potências, passando pela expansão francesa napoleônica e pela Inglaterra se afirmando como nação mais poderosa e desenvolvida no sistema internacional. Segundo List, esta mostrava clara supremacia naval, manufatureira, comercial, política e ideológica, trabalhando para influenciar a opinião pública no exterior e defender seus interesses propagando a teoria liberal de Smith. Do outro lado do Atlântico Norte, destacava-se a ascensão dos EUA (ex-colônia independente), a qual List estudou de perto e passou parte de sua vida, após seu exílio político. List foi idealizador e articulador político do protecionismo e da formação da união aduaneira (Zollverein) e política da Alemanha. Pensou como economias atrasadas, como Alemanha e EUA, poderiam superar esta condição diante de nações mais adiantadas, especialmente a Inglaterra, em termos de poder e riqueza. Embora não estivesse vivo para ver as revoluções de 1848 e a política de Bismarck, List sem dúvida é um dos construtores da Alemanha moderna. Como ele mesmo afirma, sua teoria parte da história e da realidade, observando experiências econômicas mal e bem-sucedidas, especialmente a da Inglaterra. Sua visão é marcada pela sua experiência nos EUA, onde estabeleceu contato e foi influenciado pelas ideias de Hamilton e do Sistema Americano de Economia Política, engajando-se no debate e escrevendo parte de sua $\mathrm{obra}^{8}$. Sem dúvida, a rivalidade com a Inglaterra tem papel central nesta, observando que, através de sua posição superior, vinha promovendo seu imperialismo e acordos de livre comércio benéficos a suas indústrias na Europa, bloqueando a expansão alemã.

List (1841, p.91) define Economia Política como a ciência que limita seu ensinamento a investigar como determinada nação, diante das suas próprias condições e circunstâncias específicas e das vigentes no mundo, pode obter a melhora das suas condições econômicas, a prosperidade, a civilização e o poder, por meio da articulação dos seus fatores e atividades econômicas. Ele enxergava uma ampla correlação entre o poder político (incluindo a segurança e a autonomia nacionais) e o poder industrial. List observa que o comércio exportador de manufaturas é uma forma de aumentar a produção, a riqueza, o poder e a influência de uma nação. Ao seguir Hamilton, List $(1827,1841)$ aponta o protecionismo e o desenvolvimento industrial como fundamentais para o progresso sistêmico de todas as atividades econômicas de um país, a formação de um mercado interno seguro, pujante e co-

\footnotetext{
${ }^{8}$ Em 1827, Charles Ingerssol, Vice-Presidente da "Sociedade da Filadélfia para a Promoção da Indústria Nacional", encomendou a List a elaboração de um documento de defesa do protecionismo industrial a ser apresentado na Convenção Nacional dos Protecionistas, que originou suas "doze cartas" publicadas no jornal National Gazette da Filadélfia, um dos mais importantes do país. Tais cartas formaram a base do que List chama de "seu sistema" e formaram o seu livro Outlines of American Political Economy.
} 
nectado, e a superação do atraso. Em relação à atividade manufatureira, a atividade agrícola possui menor grau de propensão à divisão do trabalho e baixa capacidade relativa de absorver novas tecnologias (máquinas e conhecimentos) - o que leva a retornos crescentes menores. Mas quando ambas estão presentes, as atividades agrícolas beneficiam-se não só das tecnologias, mas também por não sofrerem com a irregularidade dos mercados e interesses externos, muitas vezes bloqueados pelas frequentes guerras. Os ganhos conjuntos das atividades e grupos econômicos na manufatura e na agricultura fundamentam as possibilidades do estabelecimento de harmonia de interesses internos na sua visão, inspirada nos escritos de pais fundadores dos EUA, como Hamilton e Carey ${ }^{9}$. List viveu e sofreu intensamente as disputas políticas internas na Alemanha, assim como observou as vividas nos EUA, que buscavam entravar políticas industrializantes.

A essência de sua forma dinâmica de pensar o desenvolvimento nacional está na sua visão de que para cada nação específica, e para cada estágio de desenvolvimento, deve haver uma política e cuidados diferenciados com a indústria. Sua teoria é baseada em vantagens dinâmicas, que podem ser criadas mediante políticas adequadas ${ }^{10}$. Ele defendia a proteção à indústria nascente e a setores estratégicos, dos quais o Estado não poderia deixar de cuidar por questões de interesse nacional - incluindo a indústria de defesa. Ao estudar a história da ascensão inglesa, mostra que a intervenção estatal e o protecionismo foram amplamente utilizados em seu processo de desenvolvimento industrial e aumento de poder.

List (1841, p.101) define as forças produtivas da nação como: "a harmonia do conjunto de leis e instituições; poder político nacional; segurança nacional e ordem pública; forças morais e intelectuais; cooperação harmônica entre indústria, comércio e agricultura; infraestrutura e poderio naval; e, sobretudo, uma indústria diversificada, ativa e florescente conduzindo as forças produtivas nacionais”. Para ele, as forças produtivas são causas da riqueza e mais importantes do que a própria riqueza; e uma nação deve produzir poderes produtivos, não valores de troca. $\mathrm{O}$ ponto central da obra de List é nação e a nacionalidade, e a partir daí analisar o desenvolvimento, o poder e a riqueza. Ele aponta a necessidade do estudo da "Economia Nacional", em oposição ao que chamou de "economia individual" e "economia cosmopolita", baseadas nas ideias de paz universal, "mão invisível" e livre comércio entre as nações, derivadas da obra de Smith, ignorando questões de assimetrias de poder, guerras e interesses nacionais. A preocupação central de List é com o poder, embora conectado ao bem-estar. Para List, poder e riqueza são indissociáveis e atuam de forma recíproca um sobre o outro, sendo o primeiro de maior importância:

\footnotetext{
${ }^{9}$ Ver Henry Carey, "Excerpts from The Harmony of Interests: Agricultural, Manufacturing \& Commercial” (1851), disponível em: http://www.let.rug.nl/usa/documents/1851-1875/the-harmony-ofinterests/.

${ }^{10}$ Para List, somente em uma nação em estágio muito inicial (barbárie), ou com alto grau de desenvolvimento, o livre comércio seria benéfico. Para nações em processo de desenvolvimento, o protecionismo seria benéfico para o sistema econômico como um todo, para as forças produtivas e para o poder da nação.
} 
O poder é de maior importância que a riqueza. Isto é uma verdade incontestável $[. .$.$] pois uma nação, por meio do poder, não somente tem a$ capacidade de gerar novas forças produtivas, mas também de manter-se na posse da riqueza adquirida em tempos anteriores e em tempos mais recentes, e porque o inverso do poder - ou seja, a debilidade - conduz a deixar, em mão dos que nos superam em poder e potência, tudo quanto possuímos, não somente a riqueza adquirida, mas nossos poderes, nossa civilização, nossa gente, nossa liberdade, mais ainda, até nossa independência nacional [...] O objeto da economia deste corpo (a Nação) não é somente a riqueza, como ocorre na economia individual e cosmopolita, senão o poder e a riqueza, porque a riqueza nacional é aumentada e mantida mediante o poder nacional, assim como o poder nacional é aumentado e mantido pela riqueza nacional. Seus princípios dominantes são, pois, não somente econômicos, mas também políticos [...] (Idem, p.129).

List pregava a unidade nacional alemã para formar um "poder continental” por questões de poder interno e externo, e para promover a indústria e um amplo mercado interno, ligado por um amplo sistema de infraestrutura cruzando todo o território. Indo além, List (1841, p.338) previu que o destino inevitável da Europa seria se unificar pelos mesmos motivos e para defrontar o poder da Inglaterra, a qual chamou de "poder insular".

O poder é importante não só pela segurança interna e externa, mas também pela segurança e expansão comercial externa e produtiva interna. List (1841, p.124) analisa as Leis de Navegação e o benefício de sua adoção para a riqueza e o poder da Inglaterra ${ }^{11}$. Ele mostra em sua obra que a Inglaterra, pela política adotada, adquiriu poder; e pelo poder adquiriu poder de produção, e mediante seu poder de produção adquiriu riqueza. Seu poder político expandiu o raio de atuação de suas indústrias e de seu comércio, exercendo maior influência sobre outras nações. Como resultado de política comercial ainda acrescentou novo poder ao que já possuía, e novas forças produtivas às que já tinha. Isto se deve também em grande parte aos grandes avanços conseguidos nas artes e nas ciências. Assim, a relação essencial entre poder e riqueza transparece nas relações comerciais externas. Afeta a independência e a influência política de uma nação. $O$ poder e as forças produtivas são fundamentais para a segurança nacional.

A diversidade (conflitos) de interesses presente no sistema internacional, e as frequentes guerras, impõe ao Estado a necessidade de levar adiante a industrialização e a autossuficiência em bens estratégicos (especialmente os de defesa) por questões de independência política. Para List, os ganhos políticos proporcionados pela autossuficiência na produção de bens estratégicos, especialmente industriais, compensam possíveis custos econômicos decorrentes do processo de industrialização tardia (deixando de comprar mais barato de fora), especialmente em um ambiente

\footnotetext{
11 “Assim é que a Inglaterra, pela sua política, aumentou seu poderio naval, e por meio deste ampliou o raio de sua atuação manufatureira e comercial, e finalmente, por meio desta ampliação, aumentou seu poderio marítimo e suas possessões comerciais [...]” (Idem).
} 
internacional competitivo com recorrentes guerras ${ }^{12}$. Assim, tanto por questões de desenvolvimento mas essencialmente por questões de segurança, justifica uma política estatal voltada para o desenvolvimento manufatureiro e os ganhos de grupos ligados a esta, mas estabelecendo uma harmonia interna de interesses (como vimos acima) também amalgamada na ideia de uma ameaça externa. Ainda, a importância da ciência técnica e mecânica, e do conhecimento acumulado e aproveitado ao longo do tempo, manifesta-se tanto na produção quanto na guerra, na riqueza e no poder, em toda sua potencialidade (1841, p.118).

Para List (Idem), “Uma população numerosa e um território extenso dotado de múltiplos recursos naturais constituem requisitos essenciais para a nacionalidade normal; diríamos que são condições fundamentais para o cultivo intelectual, para o desenvolvimento material e para o poder político". A infraestrutura teria papel importante não só como sistema de circulação dentro do território integrando e fomentando as atividades econômicas e o mercado interno, mas também contribui para as forças produtivas e o poder, a capacidade de segurança e defesa - tal qual o argumento de Hamilton visto anteriormente. Em projetos ferroviários pioneiros de sua autoria, List pensou um sistema não só integrando a Alemanha, mas projetando seu poder para fora, na direção da Europa e do Oriente Médio, revelando sua importância geopolítica. Sua visão sobre a importância do crescimento populacional, desenvolvimento econômico e projeção de poder para o domínio e aproveitamento de recursos e espaços terrestre/marítimos dentro e além do território nacional, antecipa muitas das teses geopolíticas que aparecerão com Friedrich Ratzel e Halford Mackinder (Earle, 1986, p.251-4). List afirma que a Inglaterra, ao obter a chave dos mares, colocou uma sentinela sobre cada nação, antecipando a tese geopolítica de Alfred Mahan (1840-1914) sobre a importância do desenvolvimento do poder naval norte-americano para a conquista do "poder global” para os Estados Unidos.

\section{ALGUMAS CONSIDERAÇÕES FINAIS}

O resumo das principais ideias e propostas de Petty, Hamilton e List, para o desenvolvimento econômico dos seus países, indica claramente que nas suas visões a competição geopolítica estatal (a ameaça externa à segurança e à sobrevivência)

\footnotetext{
12 “[...] é verdade que taxas protecionistas, de início, aumentam os preços dos bens manufaturados, mas é verdade outrossim - além de ser reconhecido pela própria escola econômica dominante [escola clássica: Adam Smith e J.B. Say] - que, com o correr do tempo, pelo fato de a nação tornar-se capaz de formar por si mesma uma potência manufatureira completamente desenvolvida, esses bens passarão a ter um custo mais baixo que os bens importados. Se, portanto, as taxas protecionistas exigem o sacrifício de um valor, essa aparente perda é contrabalançada e amplamente compensada por se adquirir uma força de produção, e esta não somente assegura à nação uma quantidade infinitamente maior de bens materiais, mas também a autonomia industrial em caso de guerra. Por meio da autonomia industrial e da prosperidade interna que dela deriva, a nação fica de posse dos meios para fazer comércio externo e para ampliar sua marinha mercante, aperfeiçoar sua civilização, aperfeiçoar suas instituições internas e reforçar seu poderio externo" (List, 1841, p.117).
} 
foi sempre a grande bússola de orientação econômica das grandes potências, dando por suposto que o aumento do poder e da riqueza são dimensões inseparáveis de um mesmo processo de crescimento. Para eles, o desenvolvimento e a superação da inferioridade relativa de riqueza servem como um instrumento para superar a inferioridade relativa de poder nacional e internacional de países mais atrasados. Assim, há uma relação clara entre poder econômico (industrial, financeiro e comercial) e poder em geral, dentro de um sistema de rivalidade interestatal no qual as relações de poder entre os Estados também interferem na possibilidade de expansão da produção e do comércio. Para Petty, Hamilton e List, a relação básica entre a riqueza e o poder é de reciprocidade sinérgica, pois, em suas análises, o poder aparece como forma de garantir e aumentar a riqueza, e a riqueza como forma de aumentar o poder nacional, dentro de um sistema internacional desigual e conflitivo. A partir disso pensaram o processo de industrialização, diversificação produtiva e avanço do sistema econômico nacional como base de uma projeção econômica externa que serviria aos objetivos de poder, segurança e sobrevivência - o que Earle (1986) identificou como "fundamentos econômicos do poder militar" nas obras desses autores. Mas isso não significa uma espécie de etapismo, no sentido de que um Estado só possa se projetar externamente após resolver todos os seus problemas de desenvolvimento internos, visto que em suas reflexões, e mesmo nas experiências de seus países, a projeção externa aparece mesmo em condição de atraso e concomitante ao próprio processo de avanço econômico.

Esta "perspectiva do poder" nunca esteve presente, nem no estruturalismo latino-americano de Prebisch, nem nas teorias da dependência de Gunder Frank e de Fernando H. Cardoso e seus respectivos discípulos A problemática das lutas geopolíticas internacionais aparece pouco, e quase sempre subordinada a questões econômicas. Por isso consideramos de máxima importância, neste momento em que se volta a discutir intensamente sobre o futuro do desenvolvimento, que se resgate e reincorpore a "perspectiva do poder", da economia política clássica, na discussão teórica e política do futuro do desenvolvimento brasileiro, no século XXI.

No âmbito do debate sobre política externa dos EUA nos anos 1970, e combatendo a segmentação das ciências sociais que levou a análises com ângulos cegos sobre questões internacionais, Strange (1970) defendeu a necessidade de uma análise que junte economia internacional e política internacional - pois a primeira teria focado unicamente em questões de riqueza, enquanto a segunda em questões de poder. No âmbito deste pleito e deste debate teria sido inaugurada a disciplina de Economia Política Internacional, segundo a historiografia convencional sobre a origem da disciplina (Cohen, 2008). No entanto, se encararmos a EPI como uma reflexão ampla sobre as relações entre poder e riqueza no sistema internacional, podemos apontar a Economia Política de Petty, Hamilton e List como seus pais ou precursores. Decerto, Strange apresentou uma visão em que economia, geopolítica e segurança caminham juntas, como aprofundou em seu conceito de "poder estrutural" fundado em quatro distintas estruturas: segurança, produtiva, financeira e conhecimento. Outros autores como Klaus Knorr, no livro Power and Wealth: The Political Economy of International Power (1973), seguiram esta linha, apresentando uma abordagem ampla sobre o poder econômico nacional como basilar para o poder militar e para o poder nacional em geral, mas também sobre sua utilização 
para fins geopolíticos. Mas, na verdade, Edward Carr, ao tentar sistematizar e dar origem à "Ciência Política Internacional", manteve a linha de Hamilton e List, autores citados em sua obra Vinte Anos de Crise... de 1939. Carr, ao apresentar uma visão realista da política internacional, em um sistema caracterizado pela anarquia e conflito de interesses interestatais, observou as relações sinérgicas entre três dimensões do poder que formariam o poder em geral de um Estado: a militar, a econômica, e o poder sobre a opinião pública.

No entanto, embora estivessem atentos sobre as conexões entre economia, geopolítica e segurança nacional, nenhum desses autores da EPI estava interessado particularmente em uma reflexão sobre superação do atraso, como Petty, Hamilton e List. Por isso, observamos a necessidade de resgatar o debate latino-americano sobre desenvolvimento a partir de uma visão crítica, incluindo a dimensão geopolítica e a competição política-militar interestatal; um esforço que vem sendo empreendido no âmbito do Programa de Pós-Graduação em Economia Política Internacional (PEPI) do Instituto de Economia da UFRJ.

\section{REFERÊNCIAS BIBLIOGRÁFICAS}

ASPROMOURGOS, T. (1996) On the Origins of Classical Economics, Distribution and Value from William Petty to Adam Smith. London: Routledge.

CARR, E. H. (1939). Vinte anos de crise: 1919-39. Brasília: UnB.

COHEN, B. (2008). International Political Economy. New Jersey: Princeton University Press.

EARLE, E.M. (1986) "Adam Smith, Alexander Hamilton, Friedrich List: The economic foundations of military power". In PARET, Peter, The makers of modern strategy. New Jersey: Princeton University Press.

FIORI,J.L., org. (1999) Estados e Moedas no Desenvolvimento das Nações, Petrópolis: Editora Vozes..

FIORI, J. L. (2015). História, Estratégia e Desenvolvimento: Para uma Geopolítica do Capitalismo. Rio de Janeiro: Editorial Boitempo.

FIORI, J. L.. \& Medeiros, C.A., orgs. (2001) Polarização Mundial e Crescimento. Petrópolis, Vozes..

HAMILTON, A. (1787). Federalist. Disponível em: http://www.foundingfathers.info/federalistpapers/ hamilton.htm

HAMILTON, A. (1790). “First Report on the Public Credit”. Disponível em: https://founders.archives. gov/documents/Hamilton/01-06-02-0076-0002-0001

HAMILTON, A. (1791). Relatório sobre as Manufaturas. Rio de Janeiro: MSIA, 2000.

KNORR, K. (1973). Power and Wealth. New Jersey: Princeton University Press.

LIST, F. (1841). Sistema Nacional de Economia Política. São Paulo: Abril Cultural, 1983.

PADULA, R. (2007) "Friedrich List”. Oikos, Vol.5, no 8. Rio de Janeiro. pp. 161-167.

Petty, W. (1662). “Tratado dos Impostos e Contribuições”. In Obras Econômicas. São Paulo: Abril Cultural, 1983.

Petty, W. (1665). Verbus sapienti. São Paulo: Abril Cultural, 1983.

Petty, W. (1690). Aritmética Politica. São Paulo: Abril Cultural, 1983.

STRANGE, S. (1970) "International Economics and International Relations: A Case of Mutual Neglect”. International Affairs, Vol. 46, No. 2, pp. 304-315. 